\title{
Evaluation of a computer-assisted errorless learning-based memory training program for patients with early Alzheimer's disease in Hong Kong: a pilot study
}

\author{
This article was published in the following Dove Press journal: \\ Clinical Interventions in Aging \\ 5 June 2013 \\ Number of times this article has been viewed
}

\author{
Grace Y Lee' \\ Calvin CK Yip ${ }^{2}$ \\ Edwin CS Yu ${ }^{3}$ \\ David WK Man ${ }^{4}$ \\ 'Occupational Therapy Department, \\ Kwai Chung Hospital, ${ }^{2} \mathrm{CY}$ Functional \\ Recovery Services, ${ }^{3}$ Psychogeriatric \\ Team, Kwai Chung Hospital, \\ ${ }^{4}$ Department of Rehabilitation \\ Sciences, the Hong Kong Polytechnic \\ University, Hong Kong, People's \\ Republic of China
}

\begin{abstract}
Background: Improving the situation in older adults with cognitive decline and evidence of cognitive rehabilitation is considered crucial in long-term care of the elderly. The objective of this study was to implement a computerized errorless learning-based memory training program (CELP) for persons with early Alzheimer's disease, and to compare the training outcomes of a CELP group with those of a therapist-led errorless learning program (TELP) group and a waiting-list control group.
\end{abstract}

Methods: A randomized controlled trial with a single-blind research design was used in the study. Chinese patients with early Alzheimer's disease screened by the Clinical Dementia Rating (score of 1$)$ were recruited. The subjects were randomly assigned to CELP $(n=6)$, TELP $(n=6)$, and waiting-list control $(n=7)$ groups. Evaluation of subjects before and after testing, and at three-month follow-up was achieved using primary outcomes on the Chinese Mini-Mental State Examination, Chinese Dementia Rating Scale, Hong Kong List Learning Test, and the Brief Assessment of Prospective Memory-Short Form. Secondary outcomes were the Modified Barthel Index, Hong Kong Lawton Instrumental Activities of Daily Living Scale, and Geriatric Depression Scale-Short Form. The data were analyzed using Friedman's test for time effect and the Kruskal-Wallis test for treatment effect.

Results: Positive treatment effects on cognition were found in two errorless learning-based memory groups (ie, computer-assisted and therapist-led). Remarkable changes were shown in cognitive function for subjects receiving CELP and emotional/daily functions in those receiving TELP.

Conclusion: Positive changes in the cognitive function of Chinese patients with early Alzheimer's disease were initially found after errorless training through CELP. Further enhancement of the training program is recommended.

Keywords: Alzheimer's disease, memory training, errorless learning, computerized, early dementia

\section{Introduction}

The population in Hong Kong is ageing. A local study in Hong Kong showed that the prevalence of dementia was $9.3 \%$ for those aged 70 years or older. ${ }^{1}$ The prevalence rate of dementia is expected to double for every five years of increase in age. ${ }^{1,2}$ About 36 million people worldwide are living with dementia and this figure is expected to double every 20 years to 66 million by 2030 and to 115 million by $2050 .{ }^{3}$ Dementia, a progressive impairment of cognitive function, manifests as difficulty with memory, 
attention, thinking, and comprehension. The diagnosis of dementia is made on evidence of memory deficits plus one other cognitive deficit. ${ }^{4-7}$ One of the memory problems can be failure of prospective memory, which is important for effective performance of basic activities of daily living (ADL) and instrumental ADL in older adults and in individuals with mild cognitive impairment. ${ }^{8,9}$ There are some distinctions between time-based and event-based prospective memory. ${ }^{10}$ A meta-analysis showed deficits in prospective memory (both time-based and event-based) for mild cognitive impairment and early dementia, which were correlated with retrospective memory and executive functions. ${ }^{11}$

Cognitive training studies in healthy older adults and in patients with mild cognitive impairment or dementia have found that those with better cognitive function at baseline have better post-treatment training effects. ${ }^{12-15}$ Epidemiological and clinical trials suggest that cognitive exercise might be an effective strategy to delay the onset of cognitive impairment in older adults. ${ }^{16} \mathrm{~A}$ meta-analysis of cognitive training in patients with Alzheimer's disease showed effectiveness for restoration of learning, memory, executive functioning, activities of daily living, and general cognitive problems. ${ }^{17}$

Another evidence-based review showed that errorless learning training programs could improve memory function in patients with dementia. ${ }^{18}$ Errorless learning is a technique that can compensate for neurocognitive deficits as they relate to acquisition of new skills and abilities in rehabilitation. ${ }^{19}$ It is a better learning method compared with the trial-anderror methods used for teaching individuals with acquired memory deficits ${ }^{20}$ and in teaching everyday tasks for different diagnostic groups. A clinical study of prospective memory also showed that subjects with mild Alzheimer's disease who received seven weeks of prospective memory training, incorporated with errorless training and the spaced retrieval technique, showed a post-treatment accuracy of $90 \%$ with regard to performing prospective memory tasks successfully compared with 16\%-33\% for control subjects. ${ }^{21}$ Because it is important to ensure active participation, some errorless learning programs have been integrated with computerized rehabilitation. ${ }^{13,22-24}$ An errorless learning program was proposed for inclusion in the present study because it would bypass errors and strengthen accurate association, given that patients with Alzheimer's disease have difficulty in self-correcting errors. The training principles included: the learned task being broken into components; overlearning of components through repetition and practice; training from simple to complex with a hierarchical training of gradation and features of early success; positive immediate feedback to reinforce learning and a nonthreatening approach with hints; and incorporating vanishing cues and spaced retrieval strategies. $^{13,19,25}$

Computer-assisted cognitive intervention can be very effective in dementia. ${ }^{26,27}$ Computerized cognitive training programs (including virtual reality programs) have been applied to dementia or suspected dementia and demonstrated positive training results on memory function. ${ }^{28,29}$ The computer-assisted program was thus hypothesized to be more effective than the therapist-led program in this study. The advantages and active components of utilizing computers included: computers being capable of highly controlled presentation of stimuli in a standardized format and able to record data more accurately, consistently, and objectively than a therapist or observer; the stimuli presented by computers can be attractive, bright and colorful, which helps to engage and focus the patient's attention; the computer has unlimited patience and is very flexible in its programming. ${ }^{30,31}$ Further studies comparing computer-assisted and therapistassisted training (the content of training was identical but the training package would be delivered by therapists who gave instructions face-to-face) suggested that there were selective benefits of the former in training outcomes. ${ }^{32-35}$ The presence of an "enriched" environment (generated by multimedia programming in computerized training) would augment the learning outcomes. However, only static and passive presentation of teaching materials would be administered in therapist-administered mode, and the materials were not comparable with the vivid and colorful screen display and audio output generated from the computer. Emotional and motivational factors might also play a role in this active learning process.

Therefore, this study had two aims: firstly, to develop and implement a computerized errorless learning-based memory training program for patients with early Alzheimer's disease; and secondly, to compare the training outcomes of this program with those of a therapist-led errorless learning-based program and a waiting-list control group.

\section{Materials and methods \\ Participants}

Chinese psychogeriatric patients with a diagnosis of Alzheimer's disease (International Classification of Diseases 10th Revision or Diagnostic and Statistical Manual of Mental Disorders, 4th Edition) were screened for in psychogeriatric day hospitals, psychogeriatric outpatients at Kwai Chung Hospital, and an elderly daycare center in Kwai Chung District. Selection criteria included: age $\geq 60$ years, 
either gender, early dementia (score of 1 on screening with the Chinese Dementia Rating Scale), ${ }^{36}$ otherwise mentally stable, capable of following instructions, and an attention span of 30-45 minutes. Subjects with severe visual or hearing impairment, computer phobia, or impaired physical functioning that precluded the use of a touch-screen computer were excluded.

\section{Procedures}

Ethical approval was secured from the ethics committee of the Hong Kong Polytechnic University and clinical research ethics committee of the Kowloon West Cluster in the Hong Kong Hospital Authority. Written consent was obtained from subjects and their caregivers before assessment and training. Subjects were then allocated randomly to training with a computer-assisted errorless learning program (CELP), training with a therapist-led training program (TELP), or a waiting-list control group. Outcome evaluation of subjects before and after testing and at three-month follow-up was performed by independent blinded assessors. Most of the subjects completed all the outcome evaluations, including follow-up testing.

The intervention was led by occupational therapists with prior specialist training in using errorless memory programs. The training programs were implemented on an individual basis, approximately twice a week, with a total of 12 30-minute training sessions, which were completed in around six weeks. The CELP was run using a touch-screen notebook computer with a touch-pen input device. Therapists provided guidance if the subjects had difficulty using the computer input device or had literacy problems. Similarly, the TELP was run on an individual basis. A training manual containing colored print images was used. Therapists implementing training were provided with the same set of instructions and gave similar immediate positive feedback to subject participants, as did the CELP. The waiting-list control group received general cognitively challenging activities to perform, such as card sorting and perceptual games, or an errorful memory training program of equal duration.

\section{Instrumentation}

\section{Errorless learning-based memory training programs}

Two memory training programs were developed based on cognitive reserve and neuroplasticity theories in dementia, suggesting that the brain's neuroplasticity reserve can be enriched through cognitive experience provided by training. ${ }^{37,38}$ The programs also incorporated the technique of errorless learning, used together with spaced retrieval and vanishing cues ${ }^{12,13,18,22,39-42}$ in the CELP or TELP. The content and structure of both programs were similar, except for the mode of delivery. An experienced occupational therapist with indepth clinical experience in psychogeriatrics and an academic expert in neurocognitive training were responsible for the design of the errorless learning memory training program. The programs were designed using a culturally relevant training program with familiar daily life training content, and gradation of training was based on the level of functioning, habits, and interests of older Chinese adults with early Alzheimer's disease. The basic training principles were: the learned task was broken into components; overlearning of components through repetition and practice to enhance mastery; training from simple to complex gradation (two answers upgraded to three answers); provision of immediate positive feedback to reinforce learning; provision of a nonthreatening training atmosphere with hints provided; and incorporation of vanishing cues and spaced retrieval strategies. The rationale for adopting a specific errorless learning program is to bypass errors and strengthen accurate association, given that patients with Alzheimer's disease have difficulty self-correcting errors. One or two demonstration questions and answers were done so that subjects would feel able to follow the programs. The level of difficulty of questions was set appropriate to the level of cognitive function of the subjects. When compared with the training program not using errorless learning principles, answers to training questions might be too difficult, and without hinting cues subjects might get a wrong answer easily and become frustrated during training. For example, in simple attention training, subjects were asked to look at two pictures and confirm if they were similar or not. The participants could answer this question easily and were also trained to use the computer in a competent way during training. Because older Chinese adults like Chinese foods such as the Dim Sum, when responding to some questions in categorization, subjects had to answer if a photograph of a Dim Sum was in the same category or not. Scenarios presented during the 12 training sessions were similar to tasks in everyday life (Figure 1).

The program was structured with training components including: basic training on various memory types, including sensory memory (visual and auditory), working memory, prospective memory; memory strategies for using mnemonics (like chunking, organization, and categorization) and learning principles, and also on name/face association; advanced memory training on application of strategies to ADL, including home-making, habit training, money management, shopping, and community-living skills. Immediate positive 

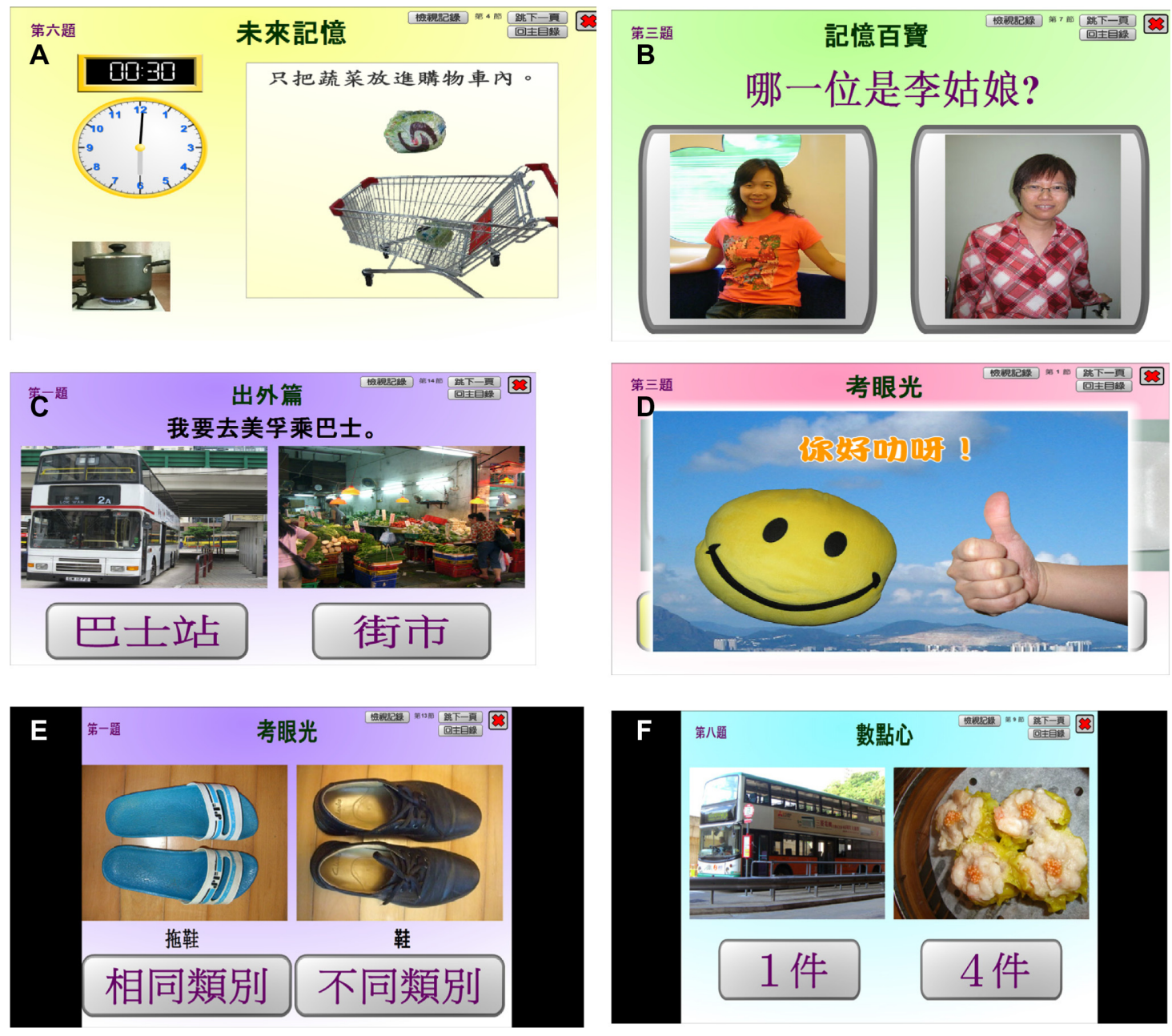

Figure I Examples of training scenarios. (A) Prospective memory and dual task training: prospective memory task, such as "switch off the stove after five minutes" while buying vegetables. (B) Face-name recognition training, combined with mnemonic memory strategies of association and spaced retrieval technique: selection photograph of same patient as shown before. (C) Memory training on community-living skills, ie, taking a bus at Mei Foo District. (D). Immediate positive reinforcement for right answer. (E) Memory training on attention and categorization of objects as being in the same group or not. (F) Memory training on working memory and counting number of Dim Sums.

feedback was integrated into the training to encourage active subject participation (see Table 1). An example of a typical training session had three parts: attention, working memory, and focus of one training theme on memory (dual task, prospective memory, name/face recognition/memory strategies, habit training, shopping, or community-living tasks, with gradation of complexity).

\section{Screening tool}

The Clinical Dementia Rating Scale (CDR) was used to screen subjects suitable for inclusion in the present study. The CDR is a widely used global assessment instrument for staging the severity of dementia, ${ }^{36}$ and takes the form of a semistructured interview with the patient and caregiver. ${ }^{43}$ A CDR score of 1 indicates that a person has mild dementia. Participants with a CDR score of 1 after assessment using the Chinese version of the CDR were recruited for this study.

\section{Primary outcome measures}

Primary outcomes measures used pre-test, post-test, and at the three-month follow-up evaluation were as follows.

\section{Mini-Mental State Examination}

In this study, we used a validated Chinese version of the Mini-Mental State Examination (MMSE) which assesses orientation, memory, visual-spatial copying, and language. The MMSE was developed by Folstein et $\mathrm{al}^{44}$ and is a well known cognitive screening tool in the elderly. ${ }^{45}$ Scores range from 0 to 30, with a higher score indicating better cognitive function. With reference to the educational background of older adults, different cutoff scores are used for dementia: a score $\leq 22$ for those with more than two years of education; a score $\leq 20$ for those with $1-2$ years of education; and a score $\leq 18$ for those with no education. The reported sensitivity of the test was $97.5 \%$ and the specificity 
Table I Outline of 12 sessions of individualized 30-minute errorless learning memory training

\begin{tabular}{|c|c|}
\hline Session & Training theme and content \\
\hline I & $\begin{array}{l}\text { Sensory memory: attention and working memory training I (counting of fruit), dual task (counting of fruit and hearing the sound } \\
\text { of a cat), delayed recall of daily objects }\end{array}$ \\
\hline 2 & $\begin{array}{l}\text { Sensory memory: attention and working memory training I (counting of fruit), dual task (counting of fruit and hearing the sound } \\
\text { of a cat), delayed recall of daily objects }\end{array}$ \\
\hline 3 & $\begin{array}{l}\text { Working memory: attention and working memory training I (counting of fruit), dual task (counting of fruit and hearing the sound } \\
\text { of a cat), delayed recall of sentences (basic), calculation task }\end{array}$ \\
\hline 4 & $\begin{array}{l}\text { Prospective memory: attention and working memory training I (counting of fruit), prospective memory and simultaneous task, } \\
\text { delayed recall of sentences (advanced), calculation task }\end{array}$ \\
\hline 5 & $\begin{array}{l}\text { Prospective memory: attention and working memory training II (counting of persons and Dim Sums), prospective memory and } \\
\text { simultaneous task, delayed recall of sentences (advanced) }\end{array}$ \\
\hline 6 & $\begin{array}{l}\text { Memory strategy (face-name): attention and working memory training II (counting of persons and Dim Sums), mnemonics and } \\
\text { strategies on face-name recognition/association and recall and organization }\end{array}$ \\
\hline 7 & $\begin{array}{l}\text { Memory strategy (face-name): attention and working memory training II (counting of persons and Dim Sums), mnemonics and } \\
\text { strategies on face-name recognition/association and recall and organization }\end{array}$ \\
\hline 8 & $\begin{array}{l}\text { Memory strategy (home-making and habit training): attention and working memory training II (counting of persons and Dim } \\
\text { Sums), mnemonics and strategies on organization/suitable placing of objects at home }\end{array}$ \\
\hline 9 & $\begin{array}{l}\text { Memory strategy (home-making and habit training): attention training, categorization, and working memory III (money recognition } \\
\text { and counting), mnemonics and strategies on organization/suitable placing of objects at home }\end{array}$ \\
\hline 10 & $\begin{array}{l}\text { Memory strategy (shopping and money management): attention training, categorization, and working memory III (money } \\
\text { recognition and counting) and shopping strategies (delayed recall and money exchange) }\end{array}$ \\
\hline 11 & $\begin{array}{l}\text { Memory strategy (shopping and money management): attention training, categorization, and working memory III (money } \\
\text { recognition and counting) and shopping strategies (delayed recall and money exchange) }\end{array}$ \\
\hline 12 & $\begin{array}{l}\text { Memory strategy (community-living skills): attention training, categorization, and working memory III (money recognition and } \\
\text { counting) and application of community-living skills in use of transport and money exchange }\end{array}$ \\
\hline
\end{tabular}

was $97.3 \%$. The reported test-retest reliability was 0.78 and the inter-rater reliability was 0.99 .

\section{Mattis Dementia Rating Scale}

The Chinese version of the Mattis Dementia Rating Scale $(\mathrm{CDRS})^{46}$ was used in this study. The CDRS consists of five subscales, ie, attention, initiation/preservation, construction, conceptualization, and memory. A total score of 144 with a cutoff score of 112 was used to differentiate persons with dementia. The cutoff score versus full score for the subscales were: 29/37 for attention, 26/37 for initiation/perseverance, 3/6 for construction, 28/39 for conceptualization, and 18/25 for memory. More detailed outcome measures could be evaluated pretest and post-test depending on the intervention used. The sensitivity and specificity of the score was $80.0 \%$ and $91.6 \%$, respectively. The Cronbach's $\alpha$ for reliability was 0.89 .

\section{Hong Kong List Learning Test}

The Hong Kong List Learning Test (HKLLT) ${ }^{47}$ is a Chinese verbal learning test, which was developed in Hong Kong and consists of two 16-word lists in which all of the words are two-character nouns. The words are from four categories and are randomly organized. The test consists of three immediate recall trials, and two delayed recall trials (10 and 30 minutes).
In this study, the HKLLT- Form A with random conditions was used.

\section{Brief Assessment of Prospective Memory-Short Form}

The short form of a Chinese assessment of prospective memory was used, ie, the Brief Assessment of Prospective Memory-Short Form (BAPM) $)^{29,48}$ with 16 questions covering aspects on basic self-care and instrumental ADL. Each question was scored 1 to 5, where a lower score indicates better functioning for elderly subjects.

\section{Secondary outcome measures Geriatric Depression Scale-Short Form}

The validated Cantonese version of the Geriatric Depression Scale-Short Form (GDS) ${ }^{49}$ was used in this study. ${ }^{50} \mathrm{~A}$ lower score indicates better subject mood. A score $\geq 8$ (of 15) indicates the possibility of depression.

\section{Chinese version of the Modified Barthel Index}

The total score on the Chinese version of the Modified Barthel Index (MBI) $)^{51}$ is 100 points. This is a self-care assessment instrument covers aspects such as grooming, feeding, dressing, functional mobility, toileting, bathing, and continence. 


\section{Hong Kong Lawton Instrumental Activities of Daily Living Scale}

The Hong Kong Lawton Instrumental Activities of Daily Living Scale (HKLIADL) ${ }^{52}$ evaluates aspects of communityliving skills, such as cooking, use of a telephone, use of transport, household management, and shopping. There is a total score of 27 points for nine items of community-living skills.

\section{Results}

Forty-nine psychogeriatric patients from Kwai Chung Hospital and psychogeriatric outpatient clinics were screened, and 24 meeting the research criteria were included in this study. Five dropped out of the study because of deterioration in their medical condition, leaving 19 subjects (six men and 13 women) of mean age $77.7 \pm 6.07$ (68-91) years. Seven subjects were randomly assigned to CELP, six to TELP, and six to a waiting-list control group. Demographic characteristics and baseline mental state (MMSE), cognitive function (DRS, HKLLT, BAPM), $\operatorname{mood}(\mathrm{GDS})$, and functional status (MBI and HKLIADL) were similar between the three groups (Table 2).
Time and treatment effects of the intervention were analyzed. Because the study was a repeated-measures design, and each case was measured three times, it was necessary to analyze the time effect with adjustment of the previous measurement to prevent time becoming a confounding factor. Therefore, analysis of the time effect was done using Friedman's test (a nonparametric form of repeated-measures analysis of variance). For analysis of the treatment effect, we divided the data into between-group and within-group. The change in the treatment period (change between pretest score and post-test score) was extracted and used to test the difference between the groups to verify our hypothesis. We also conducted the within-group analysis pretest and post-test to show the effect size of each mode of treatment delivery. Friedman's test was used to analyze within-group repeated measures, with adjustment for previous measurements. The Kruskal-Wallis test was used to analyze the between-group treatment effect, and we used the change of score in the treatment period in the computation. The Wilcoxon signed rank test was used to examine the within-group treatment effect.

Table 2 Demographic data for subjects and baseline comparisons between the three treatment groups

\begin{tabular}{|c|c|c|c|c|c|c|c|}
\hline & \multicolumn{7}{|c|}{ Group $(n=19)$} \\
\hline & \multicolumn{2}{|c|}{$\begin{array}{l}\text { Computer-assisted } \\
\text { EL memory training } \\
\text { group }(n=7)\end{array}$} & \multicolumn{2}{|c|}{$\begin{array}{l}\text { Therapist-led } \\
\text { EL memory training } \\
\text { group }(n=6)\end{array}$} & \multicolumn{2}{|c|}{$\begin{array}{l}\text { Waiting-listing } \\
\text { control group } \\
(n=6)\end{array}$} & \multirow[t]{2}{*}{$P$ value ${ }^{\#}$} \\
\hline & Count & $\%$ & Count & $\%$ & Count & $\%$ & \\
\hline \multicolumn{8}{|l|}{ Gender } \\
\hline Male & 1 & 14.3 & 3 & 50.0 & 2 & 33.3 & \\
\hline Female & 6 & 85.7 & 3 & 50.0 & 4 & 66.7 & 0.40 \\
\hline \multicolumn{8}{|l|}{ Education } \\
\hline Nil & 3 & 42.8 & I & 16.7 & 2 & 33.3 & \\
\hline$<2$ years & I & 14.3 & I & 16.7 & I & 16.7 & \\
\hline $3-6$ years & 2 & 28.6 & 2 & 33.2 & I & 16.7 & \\
\hline Secondary & I & 14.3 & I & 16.7 & 2 & 33.3 & \\
\hline University & 0 & 0.00 & I & 16.7 & 0 & 0.00 & 0.97 \\
\hline \multicolumn{8}{|l|}{ Marital status } \\
\hline Divorced & 1 & 14.3 & 0 & 0.0 & 0 & 0.0 & \\
\hline Married & 2 & 28.6 & 3 & 50.0 & 3 & 50.0 & \\
\hline Single & I & 14.3 & 0 & 0.0 & I & 16.7 & \\
\hline \multirow[t]{2}{*}{ Widowed } & 3 & 42.8 & 3 & 50.0 & 2 & 33.3 & 0.999 \\
\hline & Mean & (SD) & Mean & (SD) & Mean & (SD) & $P$ value \\
\hline MMSE & 15.3 & $(2.7)$ & 17.0 & $(3.5)$ & 17.6 & (4.7) & 0.56 \\
\hline GDS & 2.5 & $(2.30)$ & 2.1 & (I.I) & 1.6 & $(2.7)$ & 0.48 \\
\hline DRS & 100.5 & $(11.3)$ & 101.5 & $(15.1)$ & 89.5 & (II.8) & 0.14 \\
\hline HKLLT & 8.1 & $(1.9)$ & 6.5 & $(2.1)$ & 9.3 & (3.8) & 0.17 \\
\hline BAPM & 1.2 & $(0.3)$ & 1.3 & $(0.4)$ & 1.3 & $(0.4)$ & 0.88 \\
\hline MBI & 97.5 & (2.5) & 96.0 & (3.7) & 96.0 & (4.7) & 0.80 \\
\hline HKLIADL & 18.5 & $(6.1)$ & 15.6 & $(5.0)$ & 11.6 & (5.5) & 0.15 \\
\hline
\end{tabular}

Notes: ${ }^{\#}$ value by Fisher Exact test; ${ }^{\# P}$ value by Kruskal-Wallis test.

Abbreviations: EL, errorless learning; SD, standard deviation; MMSE, Mini-Mental State Examination; GDS, Geriatric Depression Scale-Short Form; DRS, Dementia Rating Scale; HKLLT, Hong Kong List Learning Test; BAPM, Brief Assessment of Prospective Memory-Short Form; MBI, Modified Barthel Index; HKLIADL, Hong Kong Lawton Instrumental Activities of Daily Living Scale. 
For the time effect (the change in score over time) in each group, as indicated by Friedman's test, only the DRS $(P=0.04)$ and MBI $(P=0.02)$ in the CELP and the DRS $(P=0.03)$ in the TELP showed significant results (Table 3$)$. For the DRS score, there was an increase of 4.67 in CELP, 10.5 in TELP, and only 0.86 in the waiting-list control group on pretest and post-test evaluation.

The treatment effect was defined in this study as the change in post-test score from the pretest score. The effect of each of the variables was analyzed in the three groups using the Kruskal-Wallis test. GDS $(P=0.009)$ was the only variable that showed a statistically significant difference (Table 4 ). Better improvement was observed in the TELP group.

Moreover, a positive within-group treatment effect was found before and after testing. For CELP, there were significant positive changes in MMSE (mean change 2.67, $P=0.04$ ), DRS (mean change 4.67, $P=0.03$ ), and BAPM (mean change $-0.26, P=0.03$ ), respectively, as well as a marginal significant change in HKLLT (mean change 4.17, $P=0.06$ ). No significant differences were found in the TELP and control groups, except in MBI (mean change 2.5, $P=0.04$ ) and GDS (mean change $2, P=0.03$ ), and a marginally significant change in MMSE (mean change 1.33, $P=0.09$ ) in TELP.

The carry-forward effect was defined as the change in the three-month follow-up score from the post-test score, and no significant differences were detected between the three groups in any of the outcome variables. Deterioration in many outcome score items was observed after three months. Clearly, it was not easy to maintain improvement in cognition, function, and mood three months after completion of training (see Table 5).

Qualitative feedback from participants in this study showed that they enjoyed and liked the memory training program and that the memory strategies learnt helped them in their daily life. They also considered that learning to use a computer was not difficult and said that they would

Table 3 Friedman's test of repeated measures in each group

\begin{tabular}{|c|c|c|c|}
\hline Outcomes & $\begin{array}{l}\text { Computer-assisted EL } \\
\text { memory training group }\end{array}$ & $\begin{array}{l}\text { Therapist-led EL } \\
\text { memory training group }\end{array}$ & $\begin{array}{l}\text { Waiting-list } \\
\text { control group }\end{array}$ \\
\hline & Mean (SD) & Mean (SD) & Mean (SD) \\
\hline MMSE pretest & $17.00(3.58)$ & I7.67 (4.76) & I5.29 (2.75) \\
\hline MMSE post-test & $19.67(5.20)$ & $19.00(4.73)$ & $17.29(3.15)$ \\
\hline MMSE follow-up test & $18.00(4.29)$ & I7.67 (5.54) & $17.00(3.37)$ \\
\hline$P$ value & 0.09 & 0.46 & 0.26 \\
\hline GDS pretest & $2.17(1.17)$ & $1.67(2.73)$ & $2.57(2.30)$ \\
\hline GDS post-test & $0.67(0.52)$ & 3.67 (4.59) & $4.43(4.24)$ \\
\hline GDS follow-up test & $1.17(1.60)$ & $4.00(4.65)$ & $4.43(4.58)$ \\
\hline$P$ value & 0.5 & 0.06 & 0.4 \\
\hline DRS pretest & $101.50(15.12)$ & $89.50(11.88)$ & $100.57(11.36)$ \\
\hline DRS post-test & 106.17 (15.38) & $100.00(14.64)$ & 101.43 (12.95) \\
\hline DRS follow-up test & 99.17 (19.04) & $98.17(11.62)$ & $100.57(1 \mathrm{I} .56)$ \\
\hline$P$ value & 0.04 & 0.03 & 0.63 \\
\hline HKLLT pretest & $6.50(2.07)$ & $9.33(3.88)$ & $8.14(1.95)$ \\
\hline HKLLT post-test & 10.67 (4.97) & $13.83(5.42)$ & $9.43(2.94)$ \\
\hline HKLLT follow-up test & $9.00(3.46)$ & $13.33(4.46)$ & II.7| (5.88) \\
\hline$P$ value & 0.12 & 0.11 & 0.08 \\
\hline BAPM pretest & $1.33(0.48)$ & $1.39(0.43)$ & $1.26(0.37)$ \\
\hline BAPM post-test & $\mathrm{I} .07$ (0.13) & I.IO (0.29) & I.I8 (0.16) \\
\hline BAPM follow-up test & $\mathrm{I} .07(0.23)$ & I.3I (0.64) & $\mathrm{I} .38(0.43)$ \\
\hline$P$ value & 0.15 & 0.1 & 0.62 \\
\hline MBI pretest & $96.00(3.74)$ & $96.00(4.73)$ & $97.57(2.5 \mathrm{I})$ \\
\hline MBI post-test & $98.83(2.04)$ & $98.50(1.97)$ & $98.29(2.63)$ \\
\hline MBI follow-up test & $99.17(2.04)$ & $98.50(2.35)$ & $99.57(1.13)$ \\
\hline$P$ value & 0.02 & 0.46 & 0.29 \\
\hline HKLIADL pretest & I5.67 (5.0I) & I I.67 (5.54) & $18.57(6.13)$ \\
\hline HKLIADL post-test & I 7.83 (5.49) & 14.17 (4.12) & I 6.43 (7.57) \\
\hline HKLIADL follow-up test & |4.67 (4.76) & $14.83(6.01)$ & $16.86(5.93)$ \\
\hline$P$ value & 0.4 & 0.42 & 0.54 \\
\hline
\end{tabular}

Note: $P$ value by Friedman's test.

Abbreviations: EL, errorless learning; SD, standard deviation; MMSE, Mini-Mental State Examination; GDS, Geriatric Depression Scale-Short Form; DRS, Dementia Rating Scale; HKLLT, Hong Kong List Learning Test; BAPM, Brief Assessment of Prospective Memory-Short Form; MBI, Modified Barthel Index; HKLIADL, Hong Kong Lawton Instrumental Activities of Daily Living Scale. 
Table 4 Effect of treatment effect on outcome variables between and within the three treatment groups

\begin{tabular}{|c|c|c|c|c|}
\hline Outcomes & $\begin{array}{l}\text { Computer-assisted EL } \\
\text { memory training group } \\
\text { Mean (SD) }\end{array}$ & $\begin{array}{l}\text { Therapist-led EL } \\
\text { memory training group } \\
\text { Mean (SD) }\end{array}$ & $\begin{array}{l}\text { Waiting-list } \\
\text { control group } \\
\text { Mean (SD) }\end{array}$ & $P$ value \\
\hline MMSE & 2.67 (3.39) & $1.33(2.42)$ & $2(0.82)$ & 0.7 \\
\hline$P$ value ${ }^{\#}$ & 0.04 & 0.09 & 0.16 & \\
\hline GDS & I.86 (3.24) & $-1.5(1.05)$ & $2(2.53)$ & $0.009 * *$ \\
\hline$P$ value ${ }^{\#}$ & 0.06 & 0.11 & 0.03 & \\
\hline DRS & $4.67(2.88)$ & $10.5(9.7 \mid)$ & $0.86(7.73)$ & 0.16 \\
\hline$P$ value ${ }^{\#}$ & 0.03 & 0.27 & 0.55 & \\
\hline HKLLT & $4.17(5.04)$ & $4.5(3.56)$ & $1.29(1.60)$ & 0.16 \\
\hline$P$ value $\#$ & 0.06 & 0.22 & 0.07 & \\
\hline $\mathrm{MBI}$ & $2.83(2.32)$ & $2.5(3.33)$ & $0.71(1.60)$ & 0.2 \\
\hline$P$ value ${ }^{\#}$ & 0.125 & 0.04 & 0.28 & \\
\hline HKLIADL & $2.17(5.85)$ & $2.5(3.27)$ & $-2.14(4.30)$ & 0.14 \\
\hline$P$ value ${ }^{\#}$ & 0.42 & 0.11 & 0.24 & \\
\hline BAPM & $-0.26(0.5 \mathrm{I})$ & $-0.29(0.27)$ & $-0.07(0.30)$ & 0.38 \\
\hline$P$ value $\#$ & 0.25 & 0.063 & 0.69 & \\
\hline
\end{tabular}

Notes: ${ }^{P} P$ value by Wilcoxon signed rank test for within-group treatment effect; ${ }^{\prime \prime} P$ value by Kruskal-Wallis test for between-group treatment effect. Negative scores on GDS and BAPM indicate improvement. **P value $<0.0$ I.

Abbreviations: EL, errorless learning; SD, standard deviation; MMSE, Mini-Mental State Examination; GDS, Geriatric Depression Scale-Short Form; DRS, Dementia Rating Scale; HKLLT, Hong Kong List Learning Test; BAPM, Brief Assessment of Prospective Memory-Short Form; MBI, Modified Barthel Index; HKLIADL, Hong Kong Lawton Instrumental Activities of Daily Living Scale.

recommend this training program to others. The feedback was generally very positive, and some subjects expressed appreciation about being invited to participate in this individualized training program that helped them to train their memory in activities of daily life.

\section{Discussion}

Like many other studies, a positive training effect was found in these errorless training programs, whether computer-assisted or therapist-led. Patients with early Alzheimer's disease seemed to be able to use errorless learning training strategies well, with better encoding of information and retrieval of information through memory strategies reinforced in the training program..$^{18,22,40,43,53,54}$

Improvement in CELP was more remarkable for cognitive function (MMSE, DRS, and BAPM) and, to a certain extent, daily functioning, as reflected by MBI. Computerassisted errorless training programs have the advantage of

Table 5 Carryover effect of outcome variables between and within the three treatment groups

\begin{tabular}{|c|c|c|c|c|}
\hline & $\begin{array}{l}\text { Computer-assisted EL } \\
\text { memory training group } \\
\text { Mean (SD) }\end{array}$ & $\begin{array}{l}\text { Therapist-led EL } \\
\text { memory training group } \\
\text { Mean (SD) }\end{array}$ & $\begin{array}{l}\text { Waiting-list } \\
\text { control group } \\
\text { Mean (SD) }\end{array}$ & $P$ value \\
\hline MMSE & $-1.67(3.39)$ & $-1.33(3.14)$ & $-0.29(2.21)$ & 0.57 \\
\hline$P$ value ${ }^{\#}$ & 0.21 & 0.28 & 0.75 & \\
\hline GDS & $0.50(1.38)$ & $0.33(0.82)$ & $0.00(1.53)$ & 0.58 \\
\hline$P$ value ${ }^{\#}$ & $0.4 I$ & 0.32 & 0.99 & \\
\hline DRS & $-7.00(5.48)$ & $-1.83(7.99)$ & $-0.86(5.08)$ & 0.42 \\
\hline$P$ value ${ }^{\#}$ & 0.22 & 0.28 & 0.59 & \\
\hline HKLLT & $-1.67(2.94)$ & $-0.50(4.85)$ & $2.29(4.50)$ & 0.23 \\
\hline$P$ value ${ }^{\#}$ & 0.21 & 0.79 & 0.17 & \\
\hline $\mathrm{MBI}$ & $0.33(0.82)$ & $0.00(3.63)$ & $1.29(3.15)$ & 0.73 \\
\hline$P$ value $^{\#}$ & 0.32 & 0.99 & 0.36 & \\
\hline HKLIADL & $-3.17(3.76)$ & $0.67(4.13)$ & $0.43(2.23)$ & 0.15 \\
\hline$P$ value ${ }^{\#}$ & 0.09 & 0.68 & 0.59 & \\
\hline BAPM & $0.00(0.23)$ & $0.20(0.50)$ & $0.20(0.35)$ & 0.67 \\
\hline$P$ value ${ }^{\#}$ & 0.99 & 0.47 & 0.23 & \\
\hline
\end{tabular}

Notes: ${ }^{P}$ value by Wilcoxon signed rank test for within-group carryover effect; ${ }^{\prime} P$ value by Kruskal-Wallis test for between-group carryover effect. Negative scores on GDS and BAPM indicate improvement.

Abbreviations: EL, errorless learning; SD, standard deviation; MMSE, Mini-Mental State Examination; GDS, Geriatric Depression Scale-Short Form; DRS, Dementia Rating Scale; HKLLT, Hong Kong List Learning Test; BAPM, Brief Assessment of Prospective Memory-Short Form; MBI, Modified Barthel Index; HKLIADL, Hong Kong Lawton Instrumental Activities of Daily Living Scale. 
providing more audiovisual feedback from the computer program to reinforce the learning of memory strategies. Subjects in the CELP group use computers in training, and mastery of the computer program was thought to enhance their sense of achievement; certainly they took pride in being able to show others that they could operate the computer, even though they were new users. Subjects were found to be highly motivated to attend the full training program as scheduled.

For TELP, more remarkable changes in outcomes were found from an emotional and functional point of view, as shown by improvements in GDS and MBI. This might be due to the fact that TELP was an individualized interactive treatment, with a more personalized and patient-centered approach. Occupational therapists could be more flexible and give immediate support and guidance to subjects when they anticipated memory problems from their clinical observation. Positive feedback was provided promptly and flexibly. This may encourage more active learning in patients with Alzheimer's disease and better self-efficacy than errorless learning training alone. ${ }^{54}$ Some subjects might have had literacy problems during some subtheme training sessions on delayed recall, so the therapist would give support by reading out some simple sentences according to the pace of learning in individual subjects. In conducting TELP, subjects with early Alzheimer's disease were observed to have difficulty in managing the memory training and dual tasks, so needed more guidance and support in these training sessions. This might be explained partly by attention problems in subjects who had difficulty in encoding simultaneous information in the training session. Therefore, extra support was often given by the therapist helping with the implementation of this errorless learning memory program.

There were pros and cons in using CELP in these patients with early Alzheimer's disease. The computer-assisted program was more standardized, with very interactive visual and auditory elements that reinforced errorless learning. Graduation of the program could be built in. For example, with increasing difficulty of training, delayed recall is likely to take longer and require various prompting cues in prospective memory training sessions. More regular stimulating positive feedback could be integrated into the training program. This would save time spent by the therapist and provide quality individualized memory training programs for patients with dementia. However, some patients with early Alzheimer's disease might need more individual guidance and support to complete a structured memory training program.
This study showed initial positive results for both the CELP and TELP programs. More innovative and creative cognitive training programs might be developed later for healthy older adults or clients with mild cognitive impairment to enhance brain health and reduce the risk of older adults developing dementia. Probably as a result of limitations in the intensity and duration of the training program and the small sample size, some intervention outcomes did not achieve statistical significance, eg, scores on MMSE in TELP and scores on MBI and GDS in CELP. It is suggested to increase the number of training sessions from 12 to 15 , with some training sessions lengthened gradually from around 30 minutes to 45 minutes when subjects have increased their attention span. Errorless learning, repetition, an active learning mode with familiar daily life content, interactive programs, and computer-based programs are considered effective memory training strategies for patients with early Alzheimer's disease. ${ }^{26,54}$ For further improvement of the existing memory training program, three revision training sessions could be added at training sessions 5, 10, and 15 , and some training sessions could be reorganized to reinforce further and consolidate memory in patients with early Alzheimer's disease based on the errorless learning and spaced retrieval strategies. We did not compare the errorless learning program with a non-errorless learning program, so it is uncertain if the errorless learning memory strategy had a better treatment effect in our patients. This should be studied further to confirm the efficacy of CELP in patients with dementia.

\section{Conclusion}

Positive cognitive changes were found initially in Chinese patients with early Alzheimer's disease after attending an errorless learning memory training program, either through a computer-based mode or a therapist-led mode. An errorless learning memory strategy may have a better effect on cognitive function in these patients. More definitive conclusions might be reached in the future when a multicenter, randomized, controlled, larger-sized study has compared errorless and non-errorless training programs, using either a computerassisted and/or therapist-administered mode.

\section{Acknowledgments}

The authors are grateful to the staff of the occupational therapy department, the psychogeriatric team at Kwai Chung Hospital, and the subjects with Alzheimer's disease and their caregivers who supported or participated in this study. 


\section{Disclosure}

The authors report no conflicts of interest in this work.

\section{References}

1. Lam LC, Tam CW, Lui VW, et al. Prevalence of very mild and mild dementia in community-dwelling older Chinese people in Hong Kong. Int Psychogeriatr. 2008;20:135-148.

2. Lichtenberg PA, Murman DL, Mellow AM. Handbook of Dementia-Psychological, Neurological, and Psychiatric Perspectives. Hoboken, NJ: John Wiley and Sons Inc; 2003.

3. Prince M, Bryce R, Ferri C. World Alzheimer Report 2011: the benefits of early diagnosis and intervention. Alzheimer's International, 2011. Available from: http://www.alz.co.uk/research/WorldAlzheimer Report2011ExecutiveSummary.pdf. Accessed March 12, 2013.

4. Richards SS, Sweet RA. Dementia. In: Sadock BJ, Sadock VA, editors. Kaplan and Sadock's Comprehensive Textbook of Psychiatry, 8th ed. Philadelphia, PA: Lippincott Williams and Wilkins; 2005.

5. Hupper FA, Beardsall L. Prospective memory impairment as an early indicator of dementia. J Clin Exp Neuropsychol. 1993;15:805-821.

6. Thompson C, Henry JD, Rendell PG, Withall A, Broadaty H. Prospective memory function in mild cognitive impairment and early dementia. J Int Neuropsychol Soc. 2010;14:318-325.

7. Scullin M, Bugg JM, McDaniel MA, Einstein GO. Prospective memory and aging: preserved spontaneous retrieval, but impaired deactivation, in older adults. Mem Cognit. 2010;39:1232-1240.

8. Gold D. An examination of instrumental activities of daily living assessment in older adults and mild cognitive impairment. J Clin Exp Neuropsychol. 2012;34:11-34.

9. Weston A, Barton C, Lesselyong J, Yaffe K. Functional deficits among patients with mild cognitive impairment. Alzheimers Dement. 2012;7: 611-614.

10. Einstein GO, McDaniel MA. Normal aging and prospective memory. J Exp Psychol Learn Mem Cogn. 1990;21:717-726.

11. Van den Berg E, Kant N, Postma A. Remember to buy milk on the way home! A meta-analytic review of prospective memory in mild cognitive impairment and dementia. J Int Neuropsychol Soc. 2012;18:706-716.

12. Clare L, Woods RT, Moniz Cook ED, et al. Cognitive training and cognitive rehabilitation for people with early-stage dementia. Rev Clin Gerontol. 2003;13:75-83.

13. Clare L. Rehabilitation of people with dementia. In: Wilson BA, editor. Neuropsychological Rehabilitation: Theory and Practice. Lisse, The Netherlands: Swets and Zeitlinger Publishers; 2003.

14. Mimura M, Komatsu S. Cognitive rehabilitation and cognitive training for mild dementia. Psychogeriatrics. 2007;7:137-143.

15. Lam LC, Lui VW, Luk DN, et al. Effectiveness of an individualized functional training program on affective disturbances and functional skills in mild and moderate dementia - a randomized control trial. Int J Geriatr Psychiatry. 2010;25:133-141.

16. Valenzuela M, Sachdev P. Can cognitive exercise prevent the onset of dementia? Systematic review of randomized clinical trials with longitudinal follow-up. Am J Geriatr Psychiatry. 2009;17:179-187.

17. Sitzer DI, Twamley EW, Jeste DV. Cognitive training in Alzheimer's disease: a meta-analysis of the literature. Acta Psychiatr Scand. 2006; 114:75-90.

18. Clare L, Jones RS. Errorless learning in the rehabilitation of memory impairment: a critical review. Neuropsychol Rev. 2008;18:1-23.

19. Kern RS, Green MF, Mintz J, Linerman RP. Does 'errorless learning' compensate for neurocognitive impairments in the work rehabilitation of persons with schizophrenia? Psychol Med. 2003;33:433-442.

20. Evans JJ, Wilson BA, Schuri U, et al. A comparison of "errorless" and "trial-and-error" learning methods for teaching individuals with acquired memory deficits. Neuropsychol Rehabil. 2000;10:67-101.

21. Kixmiller JS. Evaluation of prospective memory training for individuals with mild Alzheimer's disease. Brain Cogn. 2002;49:237-241.
22. Clare L, Wilson BA, Carter G, Hodge JR. Relearning face-name associations in early Alzheimer's disease. Neurology. 2002;16: $538-547$.

23. Jokel R, Anderson ND. Quest for the best: effects of errorless and active encoding on word re-learning in semantic dementia. Neuropsychol Rehabil. 2012;22:187-214.

24. Noonan KA, Pryer LR, Jones RW, Burns AS, Lambon Ralph MA. A direct comparison of errorless and errorful therapy for object name relearning in Alzheimer's disease. Neuropsychol Rehabil. 2012;22: 215-234.

25. Germano C, Kinsella GJ. Working memory and learning in early Alzheimer's disease. Neuropsychol Rev. 2005;15:200.

26. Galante E, Venturini G, Fiaccadori C. Computer-based cognitive intervention for dementia: preliminary results of a randomised clinical trial. Gior Italiano Med Lavoro Ergon. 2007;29:B26-B32. Italian.

27. Lynch B. Historical review of computer-assisted cognitive retraining. J Head Trauma Rehabil. 2002;17:446-457.

28. Lai N, Mok C, Lin P. Efficacy of computerised cognitive training in people with early dementia - a single-blind randomised controlled trial. Presented at the Fifth International Congress of the Asian Society Against Dementia - Action, Strategies and Development. November 5-6, 2011, Hong Kong, People's Republic of China.

29. Man DW, Fleming J, Hohaus L, Shum D. Development of the Brief Assessment of Prospective Memory (BAPM) for use with the traumatic brain injury populations. Neuropsychol Rehabil. 2011;21: 884-898

30. Bracy OL, Oakes AL, Cooper RS. The effects of cognitive rehabilitation therapy techniques for enhancing the cognitive/intellectual functioning of seventh and eighth grade children. Int J Cogn Technol. 1999;4: $19-27$.

31. Tam SF, Man DW. Evaluating computer-assisted memory retraining programmes for people with post-head injury amnesia. Brain Inj. 2004; $18: 461-470$

32. Dou ZL, Ou NH, Zheng JL, Tam SF. Computerised errorless learningbased memory rehabilitation for Chinese patients with brain injury: a preliminary quasi-experimental clinical design. Brain Inj. 2006;20: 219-225.

33. Man DW, Soong WY, Tam SF, Hui-Chan CW. A randomized clinical trial study on the effectiveness of a tele-analogy-based problem-solving programme for people with acquired brain injury (ABI). Neuro Rehabilitation. 2006;21:205-217.

34. Man DW, Soong WY, Tam SF, Hui-Chan CW. Self-efficacy outcomes of people with brain injury in cognitive skill training using different types of trainer-trainee interaction. Brain Inj. 2006;20:956-970.

35. Lam LC, Lui VW, Luk DN, et al. Effectiveness of an individualized functional training program on affective disturbances and functional skills in mild and moderate dementia - a randomized control trial. Int J Geriatr Psychiatry. 2010;25:133-141.

36. Hughes CP, Berg L, Danziger WL, Cohen LA, Martin RL. A new clinical scale for the staging of dementia. Br J Psychol. 1982;140: 566-572.

37. Bell MD, Zito W, Greig T, Wexler BE. Neurocognitive enhancement therapy with vocational services: work outcome at two-year follow-up. Schizophr Res. 2008;105:18-29.

38. Berlucchi G. Brain plasticity and cognitive rehabilitation. Neuropsychol Rehabil. 2011;21:560-578.

39. Velligan DL, Kern RS, Gold JM. Cognitive rehabilitation for schizophrenia and the putative role of motivation and expectancies. Schizophr Bull. 2006;32:474-485.

40. Clare L, Wilson BA, Carter G, Breen K, Gossess A, Hodages JR. Intervening with everyday memory problems in dementia of Alzheimer's type: an errorless learning approach. J Clin Exp Neuropsychol. 2000;22: 132-146.

41. Haslam C, Gilroy D, Black S, Beesley T. How successful is errorless learning in supporting memory for high and low-level knowledge in dementia? Neuropsychol Rehabil. 2006;18:505-536. 
42. Haslam C, Hodder K, Yates P. Errorless learning and spaced retrieval: how do these methods fare in healthy and clinical populations? J Clin Exp Neuropsychol. 2011;33:432-447.

43. Nourhashemi F, Ousset PJ, Gillette-Guyonnet S, Cantel C, Andreiu S, Vellas B. A 2-year follow-up of 233 very mild (CDR 0.5) Alzheimer's disease patients (REAL.FR cohort). Int J Geriatr Psychiatry. 2008;23: 460-465.

44. Folstein MF, Folstein SE, McHugh PR. "Mini-mental state": a practical method for grading the cognitive state of patients for the clinician. J Psychiatr Res. 1975;12:189-198.

45. Chiu HFK, Lee HC, Chung WS, Kwong PK. Reliability and validity of the Cantonese version of Mini-Mental State Examination - a preliminary study. Journal of the Hong Kong College of Psychiatrists. 1994;4 Supp 2:25-28.

46. Chan AS, Choi A, Chiu H, Lam L. Clinical validity of the Chinese version of Mattis Dementia Rating Scale in differentiating of Alzheimer's type. J Int Neuropsychol Soc. 2003;9:45-55.

47. Chan A, Kwok I. The Hong Kong List Learning Test: Manual and Preliminary Norm. Hong Kong, People's Republic of China: Department of Psychology, Chinese University of Hong Kong; 1999.

48. Chau LT, Lee JB, Fleming J, Roche N, Shum D. Reliability and normative data for comprehensive assessment of prospective memory. Neuropsychol Rehabil. 2007;17:707-722.
49. Yesavage JA, Brink TL, Rose TL, et al. Development and validation of a geriatric depression screening scale: a preliminary report. J Psychiatr Res. 1983;17:37-49.

50. Wong MT, Ho TP, Ho MY, Yu CS, Wong YH, Lee SY. Development and inter-rater reliability of a standardized verbal instruction manual for the Chinese Geriatric Depression Scale-short form. Int J Geriatr Psychiatry. 2002;17:459-463.

51. Shah S. Modified Barthel Index or Barthel Index (expanded). In: Salek S, editor. Compendium of Quality of Life Instruments, Part II. Chichester, UK: Wiley and Sons; 1998.

52. Tong YC, Man WK. The validation of the Hong Kong Chinese version of the Lawton Instrumental Activities of Daily Living Scale for institutionalised elderly persons. Occup Ther J Res. 2002;22: $132-142$.

53. Donaghey CL, Millan TM, O’Neill B. Errorless learning is superior to trial and error when learning a practical skill in rehabilitation: a randomised controlled trial. Clin Rehabil. 2010;24:195-201.

54. Laffan A, Metzler-Baddeley C, Walker I, Jones RW. Making errorless learning more active: self-generation in an error free learning context is superior to standard errorless learning in people with Alzheimer's disease. Neuropsychol Rehabil. 2010;20:197-211.
Clinical Interventions in Aging

\section{Publish your work in this journal}

Clinical Interventions in Aging is an international, peer-reviewed journal focusing on evidence-based reports on the value or lack thereof of treatments intended to prevent or delay the onset of maladaptive correlates of aging in human beings. This journal is indexed on PubMed Central, MedLine, the American Chemical Society's 'Chemical Abstracts

\section{Dovepress}

Service' (CAS), Scopus and the Elsevier Bibliographic databases. The manuscript management system is completely online and includes a very quick and fair peer-review system, which is all easy to use. Visit http://www.dovepress.com/testimonials.php to read real quotes from published authors. 